\title{
Is conflict of interest in our best interest?
}

\author{
Thomas Beyer • Johannes Czernin
}

Published online: 30 March 2010

(C) The Author(s) 2010. This article is published with open access at Springerlink.com

\section{From X-rays to being X-ed out}

On 8 November 1895 Wilhelm Conrad Röntgen observed a special type of radiation that was created from an electric discharge passing through a vacuum tube. He labelled this radiation "X-rays" using the mathematical designation for something unknown. Through X-rays matter became transparent, as so vividly demonstrated by the well-known X-ray image of the hand of Röntgen's wife. Röntgen, at the time of his groundbreaking discovery was the Chair of Physics at the University of Würzburg (1888-1900). He had no financial affiliations with industry; instead he argued with them over the costs for the vacuum tubes he used for his experiments: "Ihre Röhren sind in der Tat sehr gut, aber für meine Verhältnisse zu theuer,...Ich möchte mir deshalb die Frage erlauben, ob Sie mir die Röhren nicht zu M[ark] 20 statt zu M[ark] 30 liefern könnten...Falls Sie auf meinen Vorschlag eingehen, bitte ich Sie mir für die zwei bereits verbrauchten Röhren 4 andere gleicher Qualität zu schicken...Hochachtungsvoll" (Your tubes are indeed very good but too expensive for me. ... Therefore, I would like to ask whether you could provide me with the tubes at a price of 20 Marks instead of 30 Marks ... Should you be agreeable, I like you to replace my two already used tubes with four other tubes of similar quality ... Sincerely) [1].

T. Beyer $(\square)$

cmi-experts $\mathrm{GmbH}$,

Pestalozziststr 3 ,

8032 Zurich, Switzerland

e-mail: thomas.beyer@cmi-experts.com

J. Czernin

Department of Molecular and Medical Pharmacology,

David Geffen School of Medicine at UCLA,

10833 LE Conte Ave,

Los Angeles, CA 90095, USA

e-mail: JCzernin@mednet.ucla.edu
Soon after Röntgen's invention, made solely in the realms of academic research, several manufacturers offered $\mathrm{X}$-ray tubes and helped disseminate X-ray imaging technologies among medical professionals. Röntgen does not appear to have benefited financially from his invention. The discovery of the $\mathrm{X}$-rays and their subsequent use in various, primarily medical set-ups paved the path to non-invasive diagnosis. Thus, the non-invasively invisible became visible and by that the world of medicine was changed forever.

Taking X-ray imaging a step further, Godfrey Newbold Hounsfield prototyped a workable tomographic transmission imaging device in 1968 [2]. Unlike Röntgen, Hounsfield was an industry-paid expert working at the Central Research Laboratory for Electric and Musical Industry (EMI) Ltd. in the UK since 1951. Subsequent to his inhouse research the first CT system was installed in October 1971 at the Atkinson Morley's Hospital and the first patient images were taken in 1972 [3]. Interestingly, the company EMI did not realize the potential commercial impact of the CT system and estimated a market need of 25 systems only. By 1974 already 60 EMI CT systems were installed and by 1979 more than 1,000 CT from over 20 manufacturers were installed and operational worldwide. Today the number of clinical CT systems has exceeded 50,000. One may ask, with Hounsfield's roots in industry, is the value of his invention reduced?

Next to CT other imaging modalities were developed at the same time. The beginning of modern PET, for example, dates back to the early 1970s, when Phelps and colleagues at Washington University and, independently, researchers at Brookhaven National Laboratories built the first prototypes of a ring design PET system [4, 5]. The first, and subsequently successful approach, in particular, was joined early on by EG\&G ORTEC, an Oak Ridge-based spin-off from Oak Ridge National Laboratories. The EG\&G ORTEC group provided expertise in detectors and coincidence electronics and some nuclear instrumentation modules. A prototype (PETT) was used in January 1974 for first PET- 
based acquisitions. Since the installation of the first commercial PET unit in 1976 in Los Angeles, more than 1,000 PET-only were installed, again by several manufacturers. Thus, PET imaging, invented in academia but developed in close collaboration between industry and academia was made available to patients following the rapid commercialization of the invention of this imaging concept. Does this reduce the value of an invention that was conceived in academia?

The history of single-modality tomographic imaging indicates that a close collaboration of academia and industry has fostered the fast dissemination of these imaging technologies. Commercial adoption of academic ideas for non-invasive imaging is further exemplified by the introduction of dual-modality PET/CT tomographs. The idea for combining PET and CT originated in a clinically active academic environment in Geneva and Pittsburgh [6] prior to a grant application to the National Institute of Health (NIH) in 1994 proposing to build a prototype of an integrated PET/ CT system. Of note, the grant application was supplemented by a letter of support from Dr Ronald Nutt (CEO of CTI PET Systems Inc, Knoxville, TN, USA). The PET/CT grant was funded in 1995 and during the review it was ranked in the top 1.4 percentile for that cycle of grant requests. Today, PET/CT systems are offered by 6 manufacturers and more than 5,000 PET/CT systems are installed worldwide. From its conception PET/CT imaging was a collaborative and cofunded effort between academia and industry.

Lately, combined PET/MRI imaging has become the focus of attention in medical imaging [7]. Several academic research teams have proposed PET/MR systems for animal imaging since the mid-1990s [8]. Since 2008 several companies have indicated a keen interest in exploring the clinical potential of combining PET and MRI and a few gave indications to develop fully integrated PET/MRI in the near future [9]. While early methodological developments are supported to a great extent by research grants in the US (National Institutes of Health, NIH), EU (Framework Programme, FP) and Germany (German Research Foundation, DFG), early clinical deployment of PET/MR is driven to a great extent by industry. Today, the first clinical PET/ MR prototypes are installed and being evaluated in academic research institutions $[10,11]$. In view of the significant support by industry, are the inventions of multimodality imaging of less value? Do we have to prepare for multi-morality when going multi-modality?

\section{Framing recent discussions: scrutiny or unity?}

Medical imaging technology development was almost always initiated in academia based on a clinical need. Then, in a second step, a commercial grade prototype or beta product was created, almost always in collaboration with industry [12], followed by safety and efficacy studies and, lastly, by US Food and Drug Administration (FDA) approval. One could even argue that the more complex the imaging modality in pursuit, the greater the need for even closer collaboration with industry for fast prototyping and clinical adoption. In fact, the implementation of state-of-the-art imaging in patient care and access to modern technologies throughout the developed countries is made possible only through industry-supported product developments.

However, lately industry-academia relationships have become the focus of attention with respect to discussions on conflicts of interest (COI) and compliance guidelines. A COI is considered a set of circumstances that creates a risk that professional judgment or actions regarding a primary interest will be unduly influenced by a secondary interest [13]. COI and bias are ubiquitous. In medicine they may have the potential to harm patients by introducing bias towards existing or against novel diagnostics or therapeutics. Competing interests may arise from financial, academic and personal factors [14]. Potential COI may occur at many levels in academia, industry and at their interception, in public-private partnerships or with either academic or industry experts changing sides.

Financial drivers of COI have received the most attention as they are easily described. However, nonfinancial drivers may be equally or more important. These could relate, for example, to the competitive actions among academicians when applying for scarce funding or competence awards. On a more personal level, experts could be biased when reviewing applications for grants, positions or manuscripts. These biases created from non-financial COI are much more difficult to detect, measure or even prove, but it seems obvious that neither industrial nor academic experts are immune to these [15].

\section{Potential COI in academia—how financial are they?}

We currently lack an understanding of what collaborating physicians and experts regard as appropriate or inappropriate benefits [16]. Nonetheless, we should avoid classifying experts based on the origin of their paycheck into "intrinsically malign" (i.e. big industry) and "noble seekers" (i.e. academics) [14].

Public grants

Investigators compete for federal, national and international public funding because they need to finance their research. In many instances, funding levels are among the key determinants for academic evaluations and success, and, as 
described by Stephen Quake have made universities "place their research agendas under the whims of external funding agencies" [15]. This intimate link between funding and professional advances, in our view, can at least introduce a bias in data collection and interpretation. Further, the fact that few publications with "negative results" are published should not argue against the quality of the studies. Finally, the pressure exerted by academic institutions and funding agencies to measure academic success by the accrued number of impact points only lends itself to an obstructed progression of academic innovation.

\section{Self-referral practice}

Clinically unsubstantiated self-referring practice is known to be a key element in the rising number of imaging exams and costs in health care systems worldwide [17]. While as such this may be considered bad practice, at most it does pose the risk of a COI [18] when the self-referring physician follows ownership interest under the auspices of a professional organization. One may even argue that those academic physicians with additional direct financial income from seeing private patients benefit from academic research that demonstrates the benefits of a particular diagnostic method, such as PET, that is available only to those private patients.

\section{Academic organizations}

Academic and professional organizations are not only supported by membership fees. In fact, they frequently generate their largest revenues through industry support. This again introduces the potential for a COI. As a result several associations have published transparency guidelines that state their academic mission and detail their interaction with non-academic partners.

Engaging in transparency guidelines is a prerequisite for medical associations and for the public to acknowledge the professional cooperation between all experts in this discipline. However, publishing guidelines that prepare industry for sponsorship of events or research grants on the one hand, but stating that "in the case of clinical guidelines no experts from industry or with any other commercial background may be involved" represents an imbalanced perspective on publicprivate partnerships [19].

\section{Entrepreneurial faculty}

Researchers in academia start or co-found companies to translate and transfer their inventions to the market place. This approach has several motivations [20]. The first one would be that the inventors believe that their invention is important and useful and that it, therefore, should be made available to the public. A second important motivation is, without any doubt, financial. In medicine achieving success as both academic researcher and entrepreneur requires intense dedication and commitment to excellence and the will to have an impact on patient care [12]. Therefore, we should be careful in portraying some people as less noble than others simply because they also have a financial interest. Nonetheless, the fact that academic researchers follow, at least in part, a commercial path mandates full transparency. Transparency can be achieved by declaring and acting on a potential duality or COI.

Private grants and foundations

In view of scarce public funds many researchers turn to foundations and private research funding agencies. Depending on the amount of funding requested these agencies require similar applications as public funding agencies. However, frequently the first contact to these private funds is established through high-level personal contacts and it would seem that well-informed academic teams would have a benefit over more inhibited, yet equally intellectual teams. Again, full disclosure of the research support is required, not to acknowledge the PI's talent to obtain grant support but to fully inform the reader and audience of the funding sources for the work being presented.

Industry support

Researchers who have increasing difficulties obtaining federal or public funds could gain considerable freedom and independence for their academic programmes from industry support. This is even better understood when considering the often convoluted bureaucracy involved in obtaining public funds and executing their investment in personal and research group meetings [21]. Of course, interactions between academia and industry do carry the risk of abuse, corruption and scientific misconduct. However, this risk also exists in publicly funded research as explained above.

\section{The need for intense industry-academia relationships}

Current economy and drop in federal and public funds

We live in a time of great economic difficulties. The current economic crisis affects all of us who are engaged in medical imaging: industry, with decreasing revenues and profits, and academia with steeply declining public funds for medical research.

Resources need to be consolidated. Thus, it would seem only natural for innovators and facilitators to partner (and 
they have done so in the past) under the common goal (which they are assumed to have) to strengthen medical diagnostic or therapeutic research. Industry-academia collaborations are probably the best way to support research on every level in that area. One should also keep in mind that many great scientists that were trained in academic institutions are now industry leaders; and the reverse path from industry to academia also exists.

\section{Financial power of industry}

Typically, various levels of collaboration between public and private or academic and industrial partners exist. For example, sizeable clinical trials of new drugs or imaging probes cannot be conducted without strong support and collaboration from industry. Such trials are either directly funded by industry or can, in some instances, be indirectly funded as is the case for the clinical trials network of the Society of Nuclear Medicine, which are again frequently funded by industry indirectly.

\section{Imaging guidelines}

Structured and standardized advice on when to use and how to perform selected imaging procedures is essential for the medical profession. Imaging guidelines help to shape and promote the principles of a judicious choice of imaging protocols. There is no obvious reason in excluding "all those with potentially competing interests from expert panels, and indeed, it may not be appropriate to do so, but [it] is possible to manage the consensus process in such a way that the effect of competing interests is minimized" [14]. Why should industry experts, who may well have gained expertise, such as in their previous academic career, be denied access and active participation in guidelines produced by an expert panel? The RECIST committee, for example, consists of governmental and industry experts and new guidelines on the use of RECIST, for better or worse, are based on the input of both expert groups [22]. We should move away from trading industry solely as an eternal funding body while denying the fact that experts with academic background may be employed by industry. Experts can be on either side of the fence and may provide well-justified expertise into a peer-reviewed process.

The need to translate

Academic institutions that are strapped for funds should be highly interested in establishing substantial intellectual property income. It is common practice today for universities to form technology transfer departments. However, frequently these departments act as inhibitors rather than catalysts of IP transfer [15]. Academic institutions are poorly equipped to deal with technology transfer and need to learn quickly how to best assist researchers to get their inventions to the market. For example, as any business expert knows, resisting exclusive licensing of a patent can delay significantly the time to market of an academic invention, particularly if an industry partner is at hand and has already expressed interest in that patent.

Both academic and industry partners have a keen interest in advancing the field of medical imaging [12]. From the past it is clear that for moving from an idea to a prototype, and even more so from taking a prototype to a viable instrument in clinical routine, partnering with industry is essential. An alternative to partnering with an established vendor would be to encourage academic entrepreneurs to create spin-off companies. Spin-offs are sometimes considered as a more suitable partner than a big industry partner although both types of commercial entities work along the same principles of efficient investment, healthy growth and revenue.

We are promoting that academia partners proactively with industry in order to facilitate rapid translation of promising inventions to the market. As shown throughout history, financial interests and incentives are one proven way to accelerate this translational process. Clearly inventions that never reach the market cannot have a significant impact on society.

\section{Turning COI into dualities of interest}

How can potential conflicts be best addressed? The solution is not to create a new bureaucracy aiming at regulating the placement of each industry-sponsored pencil, mouse pad or coffee cup or objecting to the acceptance of industrysupported meals, which frequently set the stage for exchanges of ideas, or at least help create a level of inter-personal trust between the collaborating sides. The only way to address COI is complete disclosure of data and adherence to the concept of peer review. In other words, the source of funding is irrelevant as long as data are disclosed, reviewed and can be verified.

So what are the practical implications for following a COI policy adequately [14]? Here we discuss and propose a set of remedies to address potential $\mathrm{COI}$ in public-private partnerships for advancing non-invasive imaging in medicine.

\section{Disclosure}

Honest disclosure of financial relationships to patients, institutions and industry is an essential first step in identifying and responding to COI. This must be complemented by full data transparency. Many academic institutions and global associations have established COI policies. COI policies govern their or their member's and employees' interactions with industry. One example is the COI 
handbook by the California State University in response to prohibiting public employees from personally benefiting at the expense of the public interest, giving detailed descriptions of five economic interests that may, upon careful judgment, lead to a disqualification of the employee from decision making processes [23].

\section{Full transparency}

Over the past 2 years most medical journals with high impact factors had COI policies for their authors available for public review [24]. For example, a new disclosure form is suggested by Drazen et al. [25] that has been adopted by all journals that are a member of the International Committee of Medical Journal Editors (ICMJE). Therein all authors submitting to any of these journals are asked to disclose four types of information with respect to the submitted manuscript. Similarly, this could be implemented for oral presentations at conferences.

We should not forget that all scientific publications can be authored by industry and/or academic experts. These publications are subject to independent examination by referees who must be encouraged to critically examine the data and claims presented [15]. However, we should be aware that full disclosure of COI of the authors, and thus their identity, may create a non-financial COI with the referee that he/she should willingly declare to the journal as well.

\section{Transparency guidelines}

Transparency guidelines should be put in place for acting within national or international professional organizations. They should be sensible and not overly prohibitive by imposing numerous unilateral restrictions on experts of academia or industry. We should keep in mind that industryacademia relationships are not unethical per se, neither for the individual nor for the institution; on the contrary, these partnerships are extremely important, necessary and a moral obligation for bringing together the best and brightest minds in medical research to the benefit of taxpayers and consumers. Then, experts and organizations and industry alike should advocate partnerships to the public as mutually beneficial platforms for advancing science and technology both in times of crisis and prosperity.

\section{Conclusion}

Medical research should be mutually beneficial for patients, industry and academia. Medical scientists envision their inventions translated into the real patient world. All of us, engaged in medical imaging, have an interest in seeing this field grow. The more we specialize, the more we expand into the unknown, the more we require funding and sponsorship: for personnel, for instrumentation, for setting up and conducting trials and test series, funding for creating a prototype and funding for adopting a potential commercial product to subsequent customer needs.

Funding can be obtained by academia from various sources and expertise can be accrued by industry through various internal and external sources. But both partners must review their relationships with respect to accepting industry merely as a source of plentiful funding (which they are not) and considering academia solely as a source of paid consultants (which they are not). Then, both partners will benefit from a compliant partnership that helps transform ideas into products.

We must make research and, if required, associated product development transparent; this holds true for funding sources from academia and government as well as from industry.

We must render public-private partnerships active and we should not shy away from drawing mutual benefits from such partnerships. Academia, and perhaps more so, national and international funding agencies must adopt ways of spending time and funds efficiently, while medical imaging industry must adopt strategies of interdisciplinary communication as witnessed in academic and clinical partnerships.

The current reflex to COI discussions is frequently Pavlovian: Collaborations are always perceived as a potential conflict. In our view, academia-industry collaborations should be considered an interest and not a conflict of interest. It is in our interest and it is our moral obligation to collaborate closely with industry to achieve rapid translation of inventions into the clinic to the benefit of our patients. It is perhaps time to analyse the damage done to health care by institutional inertia and superficial morality.

Duality of interest Thomas Beyer is a Teaching Professor at the University of Duisburg-Essen, Germany, a Research Associate at the Inselspital Bern, Switzerland and Founder, CEO and stockholder of cmi-experts $\mathrm{GmbH}$, Switzerland.

Johannes Czernin is a Professor of Molecular and Medical Pharmacology and the Chief of the Ahmanson Biological Imaging Division at the David Geffen School of Medicine at UCLA. He serves as an advisor to cmi-experts $\mathrm{GmbH}$, Switzerland, and is a founder of Momentum Biosciences and Sofie Biosciences, Los Angeles, CA, USA.

Open Access This article is distributed under the terms of the Creative Commons Attribution Noncommercial License which permits any noncommercial use, distribution, and reproduction in any medium, provided the original author(s) and source are credited.

\section{References}

1. Roentgen WC. Brief an Fa. Reiniger: Herr Reiniger, Geber und Schall. 1896 [cited 1896: http://www.bruker-axs.de/roentgen. $\mathrm{html}$ ? \&L=3]. 
2. Friedland G, Thurber B. The birth of CT. AJR Am J Roentgenol 1996;167:1365-70.

3. Hounsfield GN. Computed medical imaging. 1979 [cited 1979: http:// nobelprize.org/nobel_prizes/medicine/laureates/1979/hounsfieldlecture.pdf].

4. Phelps ME, Hoffman EJ, Mullani NA, Ter-Pogossian MM. Application of annihilation coincidence detection to transaxial reconstruction tomography. J Nucl Med 1975;16:210-24.

5. Nutt R. The history of positron emission tomography. Mol Imaging Biol 2002;4(1):11-26.

6. Townsend DW. Multimodality imaging of structure and function. Phys Med Biol 2008;53(4):R1-R39.

7. Beyer T, Pichler B. A decade of combined imaging: from a PET attached to a CT to a PET inside an MR. Eur J Nucl Med Mol Imaging 2009;36 Suppl 1:S1-2.

8. Wehrl H, Judenhofer MS, Wiehr S, Pichler BJ. Pre-clinical PET/ MR: technological advances and new perspectives in biomedical research. Eur J Nucl Med Mol Imaging 2009;36 Suppl 1:S56-68.

9. Pichler B, Kolb A, Nägele T, Schlemmer HP. PET/MRI: paving the way for the next generation of clinical multimodality imaging applications. J Nucl Med 2010;51:333-6.

10. Schlemmer H, Pichler BJ, Schmand M, Burbar Z, Michel C, Ladebeck R, et al. Simultaneous MR/PET imaging of the human brain: feasibility study. Radiology 2008;248(3):1028-35.

11. Herzog H, Pietrzyk U, Shah NJ, Ziemons K. The current state, challenges and perspectives of MR-PET. Neuroimage 2010;49 (3):2072-82.

12. Thakor NV. Bench to bedside: motivation for university industry partnership. Conf Proc IEEE Eng Med Biol Soc 2009;2009:154-6.

13. Lo B, et al. Conflict of interest in medical research, education and practice. Institute of Medicine, ed. N. Academies. Vol. 1. 2009, Washington DC: Board on Health Sciences Policy. 440.

14. Bion J. Financial and intellectual conflicts of interest: confusion and clarity. Curr Opin Crit Care 2009;15(6):583-90.
15. Quake S. Guest column: The crumbling ivory tower. The New York Times, 2009. Opinion(17. February 2010): p. http://opinion ator.blogs.nytimes.com/2009/02/24/guest-column-the-crumblingivory-tower/.

16. Ross J, Keyhani S, Korenstein D. Appropriateness of collaborations between industry and the medical profession: physicians' perceptions. Am J Med 2009;122(10):955-60.

17. Romano DH. Self-referral of imaging and increased utilization: some practical perspectives on tackling the dilemma. J Am Coll Radiol 2009;6(11):773-9.

18. Simone J. More interest in conflicts of interest. Lancet Oncol 2009;10:836-7.

19. EANM. EANM guiding principles with regard to transparency. https://www.eanm.org/abouteanm/transparency_policy.php? navId=638, 2009.

20. Jain S, George G, Maltarich M. Academics or entrepreneurs? Investigating role identity modification of university scientists involved in commercialization activity. Research Policy 2009;38:922-35.

21. Abbott A. The future of European research. Nature 2010;463 (11):722-3.

22. Eisenhauer E, Therasse P, Bogaerts J, Schwartz LH, Sargent D, Ford R, et al. New response evaluation criteria in solid tumours: revised RECIST guideline (version 1.1). Eur J Cancer 2009;45 (2):228-47.

23. University, C.S. Office of General Counsel California State University: Conflict of interest handbook. 2009 [cited http:// www.calstate.edu/hrs/policies/policies_conflictofinterest.shtml].

24. Blum JA, Freeman K, Dart RC, Cooper RJ. Requirements and definitions in conflict of interest policies of medical journals. JAMA 2009;302(20):2230-4.

25. Drazen JM, Van der Weyden MB, Sahni P, Rosenberg J, Marusic A, Laine $\mathrm{C}$, et al. Uniform format for disclosure of competing interests in ICMJE journals. N Engl J Med 2009;361(19):1896-7. 